\title{
Inovasi Organisasi Saat Pandemi COVID-19 di Universitas Bhayangkara Jakarta Raya
}

\author{
Tyna Yunita ${ }^{1,}{ }^{*}$, Murti Wijayanti ${ }^{2}$ \\ 1,2 Fakultas Ekonomi dan Bisnis, Universitas Bhayangkara Jakarta Raya; Jl. Perjuangan \\ No.81, RT.001/RW.002, Marga Mulya, Kec. Bekasi Utara, Kota Bekasi, Jawa Barat 17143 \\ tyna.yunita@gmail.com; murti.wijayanti@dsn.ubharajaya.ac.id \\ * Korespondensi: e-mail: tyna.yunita@gmail.com
}

\begin{abstract}
The condition of the COVID-19 pandemic, which spread throughout the world, caused a massive economic downturn. The importance of education and training patterns that provide results that can be applied in the real world is the main target of education. Innovation leadership, both directly and through increasing strategic compatibility, significantly improves company performance. This study aims to examine the relationship between organizational culture, leadership style, and organizational innovation mediated by the COVID-19 pandemic. Research respondents are lecturers, and employees and students involved in student organizations. The results showed that the Organization Culture and Leadership Style mediated by the condition of Pademi Covid-19 there was a significant relationship to the Innovation Organization
\end{abstract}

Keywords: Organizational Culture, Leadership Style, Pandemic COVID-19, Organizational Innovation

\section{Abstrak}

Kondisi pandemic COVID-19 yang menyebar di seluruh dunia, menyebabkan kemerosotan ekonomi secara massif. Pentingnya pola pendidikan dan pelatihan yang memberi hasil yang dapat diaplikasikan dalam dunia nyata merupakan target utama pendidikan. Kepemimpinan inovasi, baik secara langsung maupun melalui peningkatan kecocokan strategis, secara signifikan meningkatkan kinerja perusahaan. Penelitian ini bertujuan menguji hubungan antara budaya organisasi, gaya kepemimpinan, dan inovasi organisasi yang dimediasi pandemi COVID-19. Responden penelitian merupakan dosen dan karyawan serta mahasiswa yang terlibat dalam organisasi kemahasiswaan. Hasil penelitian menunjukan bahwa Organization Culture dan Leadership Style dimediasi oleh kondisi Pademi Covid-19 ada hubungan signifikan terhadap Innovation Organization.

Kata kunci: Budaya Organisasi, Gaya Kepemimpinan, Pandemi COVID-19, Inovasi Organisasi

\section{Pendahuluan}

Kondisi pandemic COVID-19 yang menyebar di seluruh dunia, menyebabkan kemerosotan ekonomi secara massif. Korupsi merupakan masalah sebelum krisis, tetapi pandemi COVID-19 telah menyebabkan kemerosotan ekonomi (Feher \& de Bidegain, 2020). Pandemi COVID-19 menjadi salah satu tantangan terbesar terkini bagi generasi kita. Penelitian etnografi membahas bagaimana COVID-19 berdampak pada maskulinitas organisasi, pada hasil penelitian (Alcadipani, 2020) menunjukkan bagaimana situasi ekstrem dapat memengaruhi, identitas gender. persepsi,dan kinerja. Lebih jauh (Alcadipani, 2020) menyatakan akademi kepolisian telah mengembangkan program pelatihan untuk membuat detektif polisi menawarkan pendekatan yang lebih baik dan tidak menghakimi bagi korban 
Submitted: 3 Juni 2020; Revised: 24 Juni 2020; Accepted: 15 Juli 2020; Published: 31 Juli 2020

kekerasan dalam rumah tangga. Para polisi dengan budaya macho menawarkan perawatan yang layak bagi korban kekerasan dalam rumah tangga. Dalam pelatihan ini didesain dengan melibatkan permainan peran agar perawatan menjadi jelas. Banyak detektif kepolisian tampaknya mengalami perubahan perilaku yang nyata setelah mengambil bagian dalam program pelatihan.

Pentingnya pola pendidikan dan pelatihan yang memberi hasil yang dapat diaplikasikan dalam dunia nyata merupakan target utama pendidikan. Situasi pandemic COVID-19 merubah pola pembelajaran. Belajar juga haruslah menyenangkan, yang tentu saja dibutuhkan keahlian seorang pemimpin dalam hal ini guru atau pendidik yang inovatif. Kondisi krisis ini merupakan krisis monumental, perhatian beralih ke persiapan selanjutnya, mengembangkan harapan pengalaman COVID-19 yang layak mendapat perhatian dari para akademisi dan praktisi (Craighead et al., 2020).

Budaya organisasi (Abdullah et al., 2014) merupakan mekanisme penting untuk menyalurkan pesan dan informasi yang akan membedakan antara pola perilaku yang diizinkan dan tidak diizinkan melalui kebijakan, keputusan, dan kegiatan perusahaan. Sebagai pengambil kebijakan, peranan pemimpin sangat menentukan arah perusahaan. Para pemangku kepentingan organisasi tampaknya jauh lebih toleran terhadap ketidakkonsistenan antara prinsip-prinsip, nilai-nilai, dan perilaku yang dianut para pemimpin dan mengharapkan para pemimpin itu untuk beroperasi pada tingkat integritas yang lebih tinggi. Organisasi (Shulhan, 2019) menjadi lebih otentik ketika mereka menyadari ketidakpastian, menerima kesalahan mereka dan mengadopsi langkah-langkah perbaikan di bawah bimbingan para pemimpin yang efektif, inspiratif, dan lebih berpengaruh di bidang bisnis. Dalam hal ini, para pemimpin otentik bekerja untuk pengembangan pribadi mereka sambil lebih ambisius, mengedepankan nilai-nilai inti dan norma-norma, disiplin diri dan termotivasi untuk mencapai tujuan bisnis dengan pengambilan keputusan strategis.

Kepemimpinan dengan cara mengubah proses dan mendukung pembuatan kelompok dapat meningkatkan pembelajaran organisasi (McDonough III, 2000). Hal ini juga dapat merangsang kreativitas dan inovasi karyawan dan tingkatkan kepercayaan diri mereka. Pendapat senada (Golmoradi \& Ardabili, 2016), faktor yang paling kuat dalam mengembangkan pembelajaran organisasi adalah gaya kepemimpinan evolusioner dan dianggap sebagai elemen utama sumber daya manusia. Kepemimpinan adalah kunci utama untuk mengarahkan efisiensi dan meningkatkan kinerja organisasi.

Studi (Carmeli et al., 2010) menguji pentingnya kepemimpinan inovasi dalam menumbuhkan kecocokan strategis organisasi dengan lingkungannya, dan meningkatkan berbagai hasil ekonomi, hubungan, dan kinerja produk. Dengan demikian mengeksplorasi bagaimana kepemimpinan inovasi memungkinkan perusahaan untuk mengubah dan beradaptasi dengan lingkungan eksternal dan dengan implikasi meningkatkan kinerjanya. Hasil menunjukkan bahwa kepemimpinan inovasi, baik secara langsung maupun melalui peningkatan kecocokan strategis, secara signifikan meningkatkan kinerja perusahaan. Implikasi untuk 
penelitian tentang kepemimpinan strategis dan inovasi dan sistem organisasi adaptif dibahas. Iklim yang kondusif untuk perubahan organisasi merupakan factor pendukung budaya organisasi yang pro-inovasi.(Szczepańska-Woszczyna, 2015).

\section{Metode Penelitian}

Penelitian ini dilakukan di Universitas Bhayangkara Jakarta Raya dengan jumlah Responden penelitian merupakan dosen dan karyawan serta mahasiswa yang terlibat dalam organisasi kemahasiswaan. Penelitian ini menggunkan metode kuantitatif, dan dengan mengkaji hubungan antara hubungan antara variabel Innovation Organization (IO), Organization Culture (OC), Pandemic Covid-19 (PD) dan Leadership Style (LS) sebagai variable moderasi. Uji statistik yang digunakan analisis Structural Equation Modelling (SEM) dengan pendekatan Partial Least Square (PLS) untuk menganalisis variabel dan menguji model berdasarkan kajian literature, melibatkan 138 responden. Model SEM pada penelitian ini akan diperlihatkan pada Gambar 1. Dengan tahapan survei sebagai berikut: Pertama melakukan test survei terhadap 30 orang responden untuk menguji materi kuesioner. Kedua dilakukan survei kepada 138 responden pada karyawan, dosen dan mahasiswa yang terlibat organisasi kampus. Dari 200 kuesioner yang dibagikan yang kembali atau memberikan feedback dan dapat diolah sebanyak 138 jawaban responden. Kami menguji model penelitian (Gambar. 1) dan beberapa hubungan mediasi yang dihipotesiskan menggunakan Parsial Least Squares Path Modeling (PLS), pemodelan persamaan struktural berbasis varian (Hair et al., 2020; Henseler et al., 2014; Sarstedt, Hair, Ringle, Thiele, \& Gudergan, 2016). PLS adalah teknik yang cocok untuk penelitian kami karena beberapa alasan; pertama, ukuran sampel $(n=138)$ relatif kecil; kedua, model penelitian ini kompleks mengenai jenis hubungan (langsung, tidak langsung dan mediasi) dalam hipotesis; Akhirnya, penelitian ini menggunakan skor variabel laten dalam analisis selanjutnya untuk tujuan prediksi. Total ada 20 pertanyaan yang diajukan kepada responden. Dan setiap item pertanyaan diukur menggunakan lima poin skala likert dimana angka 1 menunjukan "Sangat Tidak Setuju" sedangkan 7 menunjukan "Sangat Setuju Sekali".

\section{Hasil dan Pembahasan}

Dari pengembangan hipotesis diatas, dapat dibangun model penelitian sebagai berikut:

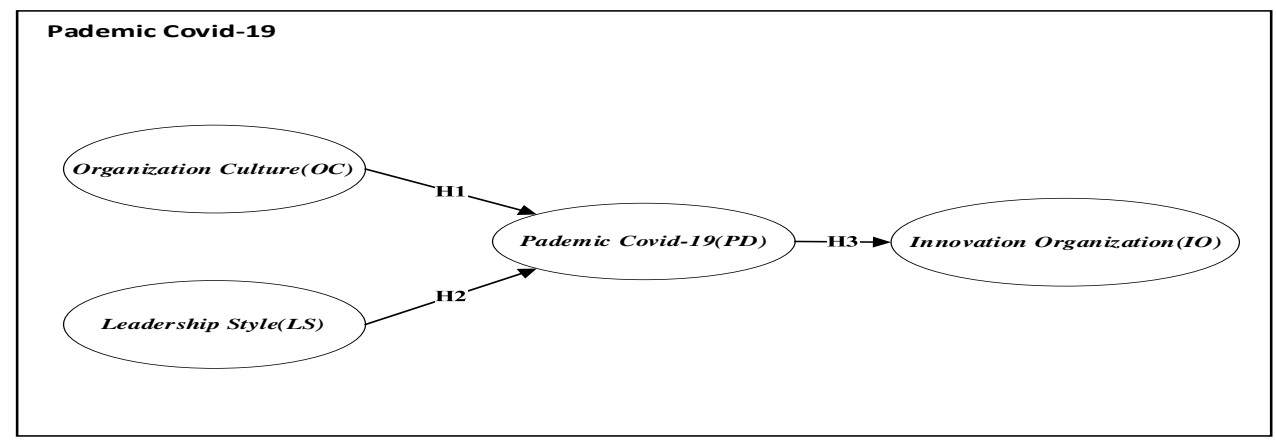

Gambar 1. Model Hipotesis Penelitian 
Berikut adalah hipotesis penelitian :

Hipotesis 1 : Ada korelali antara Pandemi COVID-19 dan Budaya Organisasi

Hipotesis 2 : Ada korelasi antara Pandemi COVID-19 dan Gaya Kepemimpinan

Hipotesis 3 : Ada korelasi antara Pandemi COVID-19 dan Inovasi Organisasi.

\section{Metode Penelitian}

Dan hasil survei kemudian dianalisis menggunakan metode SEM (Structrural Equation Modelling) melibatkan software SmartPLS Versi 3.2.9. Spesifikasi model dalam PLS-SEM termasuk didalamnya model structural dan model pengukuran. Model struktural mempresentasikan struktur jalur antar konstruk, sedangkan model pengukuran mempresentasikan hubungan masing-masing konstruk dan indicator-indikatornya (Sarstedt \& Cheah, 2019). Untuk menguji hipotesis dan kelayakan model perlu dilakukan beberapa tahapan sesuai dengan yang dilakukan oleh (Hair Jr et al., 2020). Dengan menguji validitas, rliabiliatas berdasarkan Cronbach's Alpha, Average Variance Extracted (AVE) dan Composite Reliability $(C R)$ dan pengujian model dengan melihat $\mathrm{f}^{2}$. Menurut (Hair Jr et al., 2020) pengujian model penelitian bisa menggunakan metode CFA(Confirmatory Factor Analysis) dan CCA(Confirmatory Composite Analysis). Adapun tahapan- tahapan yang dilakukan oleh (Hair $\mathrm{Jr}$ et al., 2020) adalah sebagai berikut:

\subsection{Validity and Reliability}

Pengujian Loading Indikator pada setiap variable penelitian dan signifikansinya, dengan berpedoman pada standardized loading paling tidak 0.708 dan T-Staistic \pm 1.96 signifikan twotailed test pada level $5 \%$ yaitu dengan mengesekusi prosedur bootstrapping.

Convergent Validity dihitung dengan menganalisis nilai AVE (Average Variance Explained) yang nilainya harus lebih besar dari 0.5. Sedangkan Reliabilitas dapat dinilai menggunakan pendekatan konsistensi internal dengan menganalisa $C R$ value, dimana $C R$ value harus lebih besar dari 0.7 (Raj et al., 2019).

Dari data penelitian dapat digambarkan model penelitian secara utuh sebagai berikut:

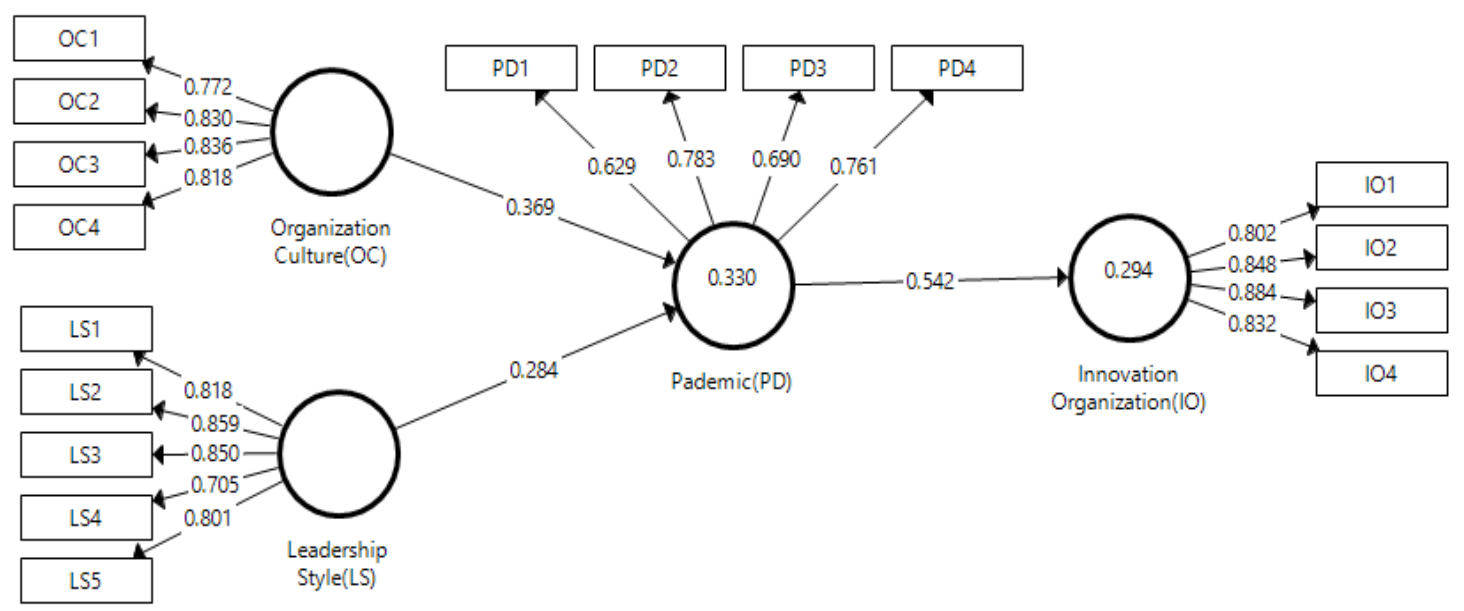

Gambar 2. Full Model Penelitian 
Dari model pada Gambar 2 sudah tidak ditemukan loading indicator masing-masing variabel $<0.7$, sehingga bisa dilakukan analisis berikutnya.

Tabel 1. Validitas \& Reliabilitas

\begin{tabular}{ccccccc}
\hline \multirow{2}{*}{ Variable } & $\begin{array}{c}\text { Cronbach's } \\
\text { Alpha }\end{array}$ & \multicolumn{2}{c}{ AVE } & \multicolumn{2}{c}{ CR } & \multirow{2}{*}{ Finding } \\
\cline { 3 - 6 } & Coef. & T-Statistic & Coef. & T-Statistic & \\
\hline IO & 0.863 & 0.709 & 21.369 & 0.907 & 65.687 & Supported \\
\hline LS & 0.868 & 0.654 & 15.960 & 0.904 & 51.646 & Supported \\
\hline OC & 0.831 & 0.663 & 15.934 & 0.887 & 46.243 & Supported \\
\hline PD & 0.684 & 0.516 & 13.281 & 0.809 & 30.608 & Supported \\
\hline
\end{tabular}

Dari keseluruhan model pengukuran juga menunjukan koefisian lebih dari 0.5 atau $5 \%$ dan signifikan. Sehingga model pengukuranya bisa dikatakan memiliki validitas dan reliabilitas baik dan dapat dilakukan proses penilaian tahap selanjutnya.

\subsection{Model Struktural}

Pengujian selanjutnya adalah menguji model strukturalnya atau inner model dengan melihat nilai $\mathrm{f}^{2}$ dengan kriteria sebagai berikut: $0.02-0.15$ menunjukan pengaruh yang kecil, $0.15-0.35$ menunjukan pengaruh menegah, $>0.35$ menunjukan pengaruh yang besar.

Dari analisis model structural didapatkan nilai $\mathrm{f}^{2}$, sebagai berikut:

Tabel 2. Structural Model

\begin{tabular}{ccccc}
\hline Relation & Loading & $\mathbf{f}^{2}$ & T-Statistic & Finding \\
\hline LS $\rightarrow$ PD & 0.284 & 0.085 & 3.331 & Supported \\
\hline OC $\rightarrow$ PD & 0.369 & 0.144 & 4.572 & Supported \\
\hline PD $\rightarrow$ IO & 0.542 & 0.416 & 8.116 & Supported \\
\hline
\end{tabular}

Dari Tabel 2. diatas menunjukan bahwa keterkaitan LS $\rightarrow$ PD, OC $\rightarrow$ PD dan PD $\rightarrow I O$ signifikan, dengan pengaruh PD $\rightarrow$ IO cukup besar besar $\left(\mathbf{f}^{2}>0.35\right)$. Kemudian dari moderasi varibel terdapat pengaruh tidak langsung seperti ditunjukan pada tabel sebagai berikut:

Tabel 3. Hubungan Variabel Mediasi

\begin{tabular}{cccc}
\hline Relations & Loading & T-Statistic & Finding \\
\hline LS $\rightarrow$ PD $\rightarrow$ IO & 0.154 & 2.958 & Supported \\
\hline OC $\rightarrow$ PD $\rightarrow$ IO & 0.200 & 3.067 & Supported
\end{tabular}

Dari Tabel 3. menunjukan hanya ada dua jalur hubungan mediasi yang diterima yaitu jalur LS $\rightarrow$ PD $\rightarrow I O$ dengan loading sebesar 0.154 dan OC $\rightarrow$ PD $\rightarrow I O$ sebesar 0.200. Sehingga bisa dijabarkan bahwa hipotesis penelitian $\mathrm{H} 1, \mathrm{H} 2$ dan $\mathrm{H} 3$ diterima.

\section{Kesimpulan}

Hasil dari penelitian ini menunjukan bahwa Organization Culture dan Leadership Style dimediasi oleh kondisi Pademi Covid-19 ada hubungan signifikan terhadap Innovation Organization. Di Universitas Bhayangkara Jakarta Raya. Penelitian ini belum bisa digeneralisasi 
karena unit penelitian ini sekupnya masih sempit atau terbatas di lingkungan kampus Universitas Bhayangkara Jakarta Raya. Sehingga untuk penelitian lebih lanjut diharapkan bisa melibatkan populasi dan sample yang lebih luas.

\section{Daftar Pustaka}

Abdullah, N. H., Shamsuddin, A., Wahab, E., \& Hamid, N. A. A. (2014). The Relationship between Organizational Culture and Product Innovativeness. Procedia - Social and Behavioral Sciences, 129, 140-147. https://doi.org/10.1016/j.sbspro.2014.03.659

Alcadipani, R. (2020). Pandemic and Macho Organizations: Wakeup Call or Business as Usual? Gender, Work \& Organization.

Carmeli, A., Gelbard, R., \& Gefen, D. (2010). The importance of innovation leadership in cultivating strategic fit and enhancing firm performance. Leadership Quarterly, 21(3), 339349. https://doi.org/10.1016/j.leaqua.2010.03.001

Craighead, C. W., Ketchen Jr, D. J., \& Darby, J. L. (2020). Pandemics and Supply Chain Management Research: Toward a Theoretical Toolbox. Decision Sciences.

Feher, C., \& de Bidegain, I. (2020). Pension Schemes in the COVID-19 Crisis: Impacts and Policy Considerations.

Golmoradi, R., \& Ardabili, F. S. (2016). The Effects of Social Capital and Leadership Styles on Organizational Learning. Procedia - Social and Behavioral Sciences, 230(May), 372-378. https://doi.org/10.1016/j.sbspro.2016.09.047

Hair Jr, J. F., Howard, M. C., \& Nitzl, C. (2020). Assessing measurement model quality in PLSSEM using confirmatory composite analysis. Journal of Business Research, 109, 101110.

McDonough III, E. F. (2000). Investigation of factors contributing to the success of crossfunctional teams. Journal of Product Innovation Management: An International Publication of the Product Development \& Management Association, 17(3), 221-235.

Raj, S., Nijjer, S., Ongsakul, V., \& Singh, H. (2019). Determinants of key facets of job satisfaction in the banking sector: applying SMART PLS and artificial neural networks. Journal for Global Business Advancement, 12(2), 298-323.

Sarstedt, M., \& Cheah, J.-H. (2019). Partial least squares structural equation modeling using SmartPLS: a software review. Journal of Marketing Analytics, 7(3), 196-202.

Shulhan, M. (2019). Effect of Authentic Leadership on Academic Atmosphere and Organizational Culture in Indonesian Islamic Higher Education. International Journal of Innovation, Creativity and Change, 7(2).

Szczepańska-Woszczyna, K. (2015). Leadership and Organizational Culture as the Normative Influence of Top Management on Employee's Behaviour in the Innovation Process. Procedia Economics and Finance, 34(15), 396-402. https://doi.org/10.1016/s22125671(15)01646-9 